\title{
Tributo, fenotipo y genealogía. Indígenas y nación en el Caribe colombiano durante el siglo XIX
}

\author{
Sergio Paolo Solano \\ Universidad de Cartagena de Indias, Colombia \\ ssolanod@unicartagena.edu.co
}

Recepción: 12 de enero de 2011 / Revisión: 19 de mayo de 2011

Aceptación: 12 de junio de 2011 / Publicación: diciembre de 2012

\section{RESUMEN}

En este artículo se estudia qué era un indígena en la región Caribe colombiana durante el siglo XIX. Se trata de un tema de interés para aquellas áreas de la geografía de este país y del resto de Latinoamérica no asociadas a la presencia de indígenas, al dárseles por extinguidos o porque se identifican a sus pobladores con otras características étnicas. Argumentamos que durante ese siglo el Estado republicano desempeñó un papel de primer orden en la definición de la identidad indígena, al igual que lo había hecho el Estado colonial, al lidiar con una relación de naturaleza étnica que tenía implicaciones institucionales. Mostramos que los indígenas sacaron provecho de los conflictos políticos entre los sectores dirigentes y de las normas republicanas.

Palabras clave: Caribe colombiano, indígenas, resguardos, nación, identidad, tributo, fenotipo, genealogía, Colombia, siglo XIX.

\section{Tribute, Phenotype and Genealogy. Indian and Nation in the Colombian Caribbean during the Nineteenth Century}

\begin{abstract}
In this paper we study what was an Indian in the Colombian Caribbean region during the nineteenth century. This is a topic of interest for those areas of the geography of this country and the rest of Latin America is not associated with the presence of Indians, to be given or be extinct because its inhabitants are identified with other ethnic characteristics. We argue that during this century, the Republican state played a leading role in defining Indian identity, as he did the colonial state, in dealing with ethnic nature relationship had institutional implications. We show that the Indians took advantage of political conflict between the leading sectors and the Republican rules.
\end{abstract}

Key words: Colombian Caribbean, Indigenous, Reservations, Nation, Identity, Tribute, Phenotype, Genealogy, Colombia, XIXth Century.

Sumario: 1. Presentación. 2. Los pueblos de indios: de la Colonia tardía a la República. 3. Indígenas: tributo, fenotipo y genealogía. 4. Reflexión final. 5. Referencias bibliográficas. 


\section{PRESENTACIÓN}

Durante la República las elites, autoridades, políticos e intelectuales tuvieron que definir qué era un indígena dadas las implicaciones políticas e institucionales que tenían las respuestas asumidas. Esta pregunta cobraba más fuerza en aquellas áreas que, como el Caribe colombiano, desde la Colonia temprana se había avanzado en la integración de las comunidades de indígenas a la sociedad mayor. Según el censo de $1777-1778$, un poco más del $18 \%$ de la población de la provincia de Cartagena ${ }^{1}$, poseían esa condición étnica, y aún el censo de 1912, que sólo contabilizó a la población masculina, señaló que el 6,5\% del total de los hombres de los departamentos de Bolívar (excluyendo al archipiélago de San Andrés y Providencia) y Atlántico correspondía a indígenas. Si incluimos igual porcentaje de mujeres, daría un total del $13 \%$ de personas de esta condición étnica, cifra aún significativa ${ }^{2}$. En consecuencia, se trata de un interrogante relevante para los actuales estudios sobre la configuración social y étnica de esta parte de la región Caribe colombiana, pues la historiografía del siglo XX dio por extinguida a esa importante franja de la sociedad y a sus resguardos durante la primera centuria republicana ${ }^{3}$.

La pregunta implica el análisis de tres aspectos relacionados. Uno está ligado al estudio de las representaciones que se hicieron los hombres políticos y letrados del primer siglo de la República sobre el indígena, en la que nos concentraremos por razones de espacio. Otro son las manipulaciones hechas por los indígenas de la identidad que les fue adscrita desde el poder. Y el último es la necesidad de recuperar las especificidades de la condición étnica de muchas comunidades del mundo agrario, las que se pierden en las representaciones construidas por los historiadores, políticos y economistas en épocas recientes que han sumido a aquéllos en el campesinado.

Para responder al interrogante planteado en este artículo argumentamos que durante la segunda mitad del siglo XIX la identidad de los indígenas del Bolívar Grande estuvo sometida a una tensión que en el largo plazo la fue deteriorando. Por una parte estaba la ideología del mestizaje como fundamento de la nación, la que pretendiendo crear una base homogénea de la nacionalidad intentó suprimir la existencia de indígenas y negros de la geografía colombiana. Ese discurso del mestizaje se ligó con el discurso liberal de la ciudadanía, colocado por encima de otras identidades. Por otro lado, estuvieron las ambivalencias de las autoridades frente a la existencia de los

\footnotetext{
1 La colonial Provincia de Cartagena de Indias abarcaba el área de la región Caribe colombiana comprendida entre el margen occidental del bajo curso del río Magdalena y el golfo de Urabá. Así se llamó hasta mediados del siglo XIX. A partir de 1857 se denominó Estado Soberano de Bolívar y a partir de 1886 Departamento de Bolívar o Bolívar Grande. Comprendía los actuales territorios de los departamentos del Atlántico, Bolívar, Sucre, Córdoba, el archipiélago de San Andrés y Providencia. En total 65.000 kilómetros cuadrados. En esta área estaban situados los resguardos indígenas de Tubará, Galapa, Malambo, Piojó, Usiacurí, Turbana, Turbaco, Zambrano, Tetón, Tacaloa, Talaigua, Chilloa, Menchiquejo, Yatí, Jegua, Guazo, Menchiquejo, Colosó, Toluviejo, Morroa, San Andrés de Sotavento, Sabaneta, Sampués, San Sebastián, Chinú, Cereté, San Nicolás de Bari, San Cipriano. Ver mapa 1.

2 Tovar, et AL, 1994, pp. 470-501, y CENSO GENERAL DE LA REPÚBLICA, 1912, pp. 32, 82 y 98-100.

3 Colpas - Mendoza, 1999, pp. 54-58; Conde, 2002, pp. 43-67. Para el caso de la Provincia de Santa Marta, un historiador ha afirmado que los indígenas renunciaron a esa identidad étnica para acogerse a la identidad republicana de la ciudadanía. SAETHER, 2005a, pp. 55-80. Para una demostración contraria ver: SOLANO, 2008, pp. 34-47; Solano - FlóREZ, 2007a, pp. 92-117; 2007b, pp. 81-89; 2009, pp. 267-295; 2011.
} 
resguardos, los intereses de las elites y de otros sectores sociales en suprimirlos. Por último, se encontraba el interés mostrado por los indígenas para que se les siguiera reconociendo esa condición étnica, y los intereses de sectores políticos del momento que veían en aquellos potenciales aliados.

En medio de esa tensión el Estado republicano jugó un papel de primer orden en la definición de la identidad indígena al igual que lo había hecho el Estado colonial, debido a que a la República le tocó lidiar con una relación de naturaleza étnica que tenía implicaciones institucionales. Los indígenas sacaron provecho de los conflictos políticos entre los sectores dirigentes ${ }^{4}$, negociando, por vía de sus mediadores y apoderados, la salvaguarda de sus intereses. La negociación permitió que se revivieran algunos criterios del siglo XVIII para establecer la identidad, introduciendo como reconocimiento de esa condición étnica la autopercepción colectiva y las relaciones de otredad, las que tuvieron efectos jurídicos y políticos muy importantes para finales de la primera centuria republicana. En consecuencia, la identidad de los indígenas también fue el resultado de una reelaboración que estos hicieron aprovechando las normas de la República para expresar sus intereses. Para ello argumentaron razones históricas tanto coloniales como republicanas, compararon el trato recibido durante la Colonia con el que les daba la República ${ }^{5}$, arguyeron derechos ancestrales y títulos primordiales, desarrollaron rituales de posesión de las tierras, promovieron acciones legales por medio de sus apoderados, mostraron los contratos de arrendamiento de sus tierras, y emprendieron acciones de hecho contra otros sectores sociales.

Con el fin de demostrar nuestro argumento combinamos el estudio las disposiciones oficiales emitidas por las autoridades del Estado Soberano de Bolívar en el decenio de 1860 para regular la vida de los resguardos, con las actitudes de los sectores interesados en abolirlos, y las respuestas dadas por los indígenas en el marco de la normatividad republicana. Como estas últimas solo se hacían visible durante los conflictos sociales que involucraban a esas comunidades, analizamos el periodo liberal (1850-1885) debido a que después de promulgada la constitución liberal de 1863 el tema de las tierras resguardadas se convirtió en el centro de un debate que permitió que afloraran los mundos de las representaciones colectivas sobre la relaciones interétnicas. En un comienzo los debates se centraron en definir si los resguardos quedaban comprendidos dentro de las políticas de desamortización de bienes de manos muertas de 1861 y de la proclamación de la libre propiedad individual y comercial de los bienes inmuebles establecida por la constitución. Sin embargo, muy rápidamente las discusiones giraron en torno a la pregunta acerca de si todavía existían los indígenas que habían llevado al Estado colonial a resguardarles la propiedad territorial. Ese desplazamiento se debió a que muchos políticos y hacendados consideraron ilegal que el Estado republicano continuara protegiendo una forma de propiedad que estaba en contravía con los principios constitucionales, la que dependía de unas consideraciones raciales. En otros términos, la disputa se centró en intentar definir qué era un indígena.

\footnotetext{
4 FALS, 1986, pp. 163-181; Flórez, 2009, pp. 49-72.

5 Memorial de varios vecinos del extinguido distrito de Malambo y resolución. Cartagena, 28-I-1869. Gaceta de Bolívar. Colección de prensa microfilmada. Biblioteca Luis Ángel Arango [en adelante BLAA].
} 
El artículo está organizado en tres partes. En la primera presentamos algunas ideas acerca de la identidad del indio bajo el régimen del resguardo colonial. En la segunda parte evaluamos las respuestas que planteadas por algunos historiadores tanto para lo que era un indígena a finales del periodo colonial, como en lo que se transformó bajo la República. En la tercera parte analizamos las discusiones entre abolicionistas y conservacionistas en torno a qué era un indígena en el Bolívar Grande durante el siglo XIX.

\section{LOS PUEBLOS DE INDIOS: DE LA COLONIA TARDÍAA LA REPÚBLICA}

Durante la temprana Colonia a los nativos de América se les llamó indios para facilitar las relaciones de interacción y subordinación, originando una alteridad que se movió entre aceptar la diversidad de las culturas y la tendencia a homogenizarlos ${ }^{6}$. Esta denominación fue asimilada por cientos de miles de nativos que quedaron bajo el control de los colonizadores, viéndose precisados a articular nuevas identidades en las que la subordinación fue uno de los elementos centrales ${ }^{7}$. En este sentido, la subalternidad les impuso los términos y contenidos elaborados por el discurso hegemónico, aunque se aprovecharan de márgenes de maniobras para resignificar el lenguaje, los discursos institucionales sobre las identidades adscritas y las prácticas del poder ${ }^{8}$. En buena medida se trató de una identidad institucionalizada, es decir, una de imagen producida e impuesta por el poder, la que tuvo sus efectos en la creación de la república de indios, con sus asentamientos e instituciones políticas y legales.

En esa categoría se vaciaron distintos significados a lo largo de la Colonia en función de los avances del mestizaje, las necesidades fiscales de la monarquía, de las actitudes de los indios y sus relaciones con otros sectores. En la Nueva Granada del siglo XVIII la identidad de aquellos como cuerpo político, social y racial estaba ligada al fenotipo, la cultura y, sobre todo, a una condición jurídica y política que desde la abolición de las encomiendas y la creación de los resguardos habían convertido a los pueblos de indios en un cuerpo político dentro de la monarquía ${ }^{9}$. En este sentido

6 Bonfil, 1970, pp. 105-124; Brading, 1998, pp. 72-97.

7 Según el estudio de Carmagnani sobre la reconstitución étnica en el área de Oaxaca (México) entre los siglo XVII y XVIII, la nueva identidad étnica fue un proceso de larga duración, “... que reelabora los elementos prehispánicos a la luz de los elementos internos y de los elementos condicionantes de las sociedades indias, favoreciendo la consolidación y la expansión de la identidad étnica. En esta forma, el proceso de reconstitución permite a las sociedades indias reelaborar y proyectar al futuro un patrimonio étnico, desarrollar una nueva racionalidad, una nueva lógica, diferente de la prehispánica, pero no por ello menos indias de la precedente". CARmagnani, 2004, pp. 13-14.

8 HÉAU, 2009, pp. 145-162.

9 SAEther, 2005, pp. 55-80. La Nueva Granada fue la única colonia española en que se llamó resguardos a los pueblos de indígenas organizados una vez se abolieron las encomiendas. Con ese término se denominaba tanto a la comunidad indígena como al territorio que le fue asignado, usualmente una circunferencia de una legua castellana de radio (4.5 kilómetros) trazada a partir de la puerta principal de la iglesia doctrinera, GonZÁLEZ, 1992, pp. 27-61. Su creación data del tránsito entre los siglos XVI y XVII cuando se suprimieron las encomiendas debido a la reducción de la población tributaria y a las continuas quejas de varios sectores por los abusos cometidos por los encomenderos y los mayordomos-administradores. Se trató del último intento hecho por las autoridades para evitar el fracaso de la política de mantener separadas la "república de blancos" (ciudades y villas de españoles) de la "república de indios", como también por proteger a la población indígena 
se trató de una identidad adscrita desde las instituciones, lo que garantizó a los indios unos derechos, en especial el control de ciertos órganos de gobierno de sus comunidades (gobernadores, capitanes, cabildos de indios) y las tierras resguardadas ${ }^{10}$.

A diferencia del área andina de la Nueva Granda donde los resguardos se crearon desde el siglo XVI, en la Costa Caribe solo en la segunda mitad del siglo XVIII las autoridades legalizaron su formación y funcionamiento. Esta tardía creación se debió a las resistencias de las elites de esta área, al carácter de frontera de la mayoría de su territorio, y al poder de negociación de las elites de Cartagena y Santa Marta que les permitía desconocer muchas de las disposiciones emanadas de las autoridades centrales de la Nueva Granada. Solo en el marco de las reformas borbónicas fue que estas últimas pudieron impulsar políticas de reformas poblacionales en las provincias del Caribe, creando los resguardos, estableciendo un nuevo sistema de tributos y protegiendo las tierras de los indios.

En este sentido, en sus orígenes el resguardo puede interpretarse como una redefinición de las condiciones de subordinación establecida por las autoridades coloniales a los indios sometidos y a las elites que controlaban las encomiendas. También representó una especie de reconsideración de las funciones y de la legitimidad del Estado colonial en el Nuevo Mundo, el que intentaba controlar y meter en cinturas a las elites y autoridades provinciales que se resistían a cualquier control ${ }^{11}$. El resultado de todo esto fue que las elites y el poder reconstruyeron al indio mediante prácticas sociales discursivas, legislaciones y mecanismos de ordenamiento jerárquico y territorial de las diferencias consideradas como raciales. Los indios también desarrollaron sus lecturas del orden socio-racial, reelaborando una diversidad de elementos de la sociedad colonial para reconstituir sus identidades, y construyeron relaciones de alteridades jerarquizadas con relación a otras comunidades de nativos, en especial con los no sometidos o "salvajes".

En consecuencia, el resguardo no representaba la cultura india primigenia, pues como espacio de repoblamiento fue el escenario de la recreación de la identidad étnica por medio de una acción consciente dirigida a organizar y jerarquizar algunos elementos que cohesionaran nuevas identidades compatibles con el sistema colonial. Los indios reacondicionaron sus relaciones sociales, la cultura, sus vínculos con el poder y con otros grupos sociales. Esto lo lograron reelaborando el universo simbólico, las formas de cohesión y la cotidianidad e inventaron unas tradiciones ${ }^{12}$. Por ende, las comunidades hicieron un uso consciente y político de uno o varios elementos que

de la extinción a que se veía abocada. Luna, 1993, pp. 22-31; Martínez, 1993, pp. 5-19; BonnetT, 2002, pp. 21-39.

10 Para México, Antonio Escobar ha propuesto que los criterios de identidad indígena en el siglo XVIII fueron el sitio de domicilio y el pago de tributo. EscoBAR, 2010, pp. 42-43.

11 La negociación de la subordinación durante la colonia fue impuesta por las necesidades fiscales de las autoridades y por los continuos conflictos entre encomenderos, mayordomos, curas doctrineros y colonos por una parte, y los indios y las autoridades centrales por otro lado. Los indios se convirtieron en vasallos del rey sin la mediación de los encomenderos, permitiéndoseles el control de los factores que servían para la reproducción de la comunidad (tierras y otros recursos naturales) y algunos órganos de autogobierno como los pequeños cabildos. Gutiérrez, 2007, pp. 45-56; GonzÁlez, 1993; Martínez, 1993, pp. 10-19; Ruiz, 1996, pp. 161-178.

12 Zambrano, 2000, pp. 195-229. 
Mapa 1. Resguardos indígenas del Bolívar Grande durante el siglo XIX

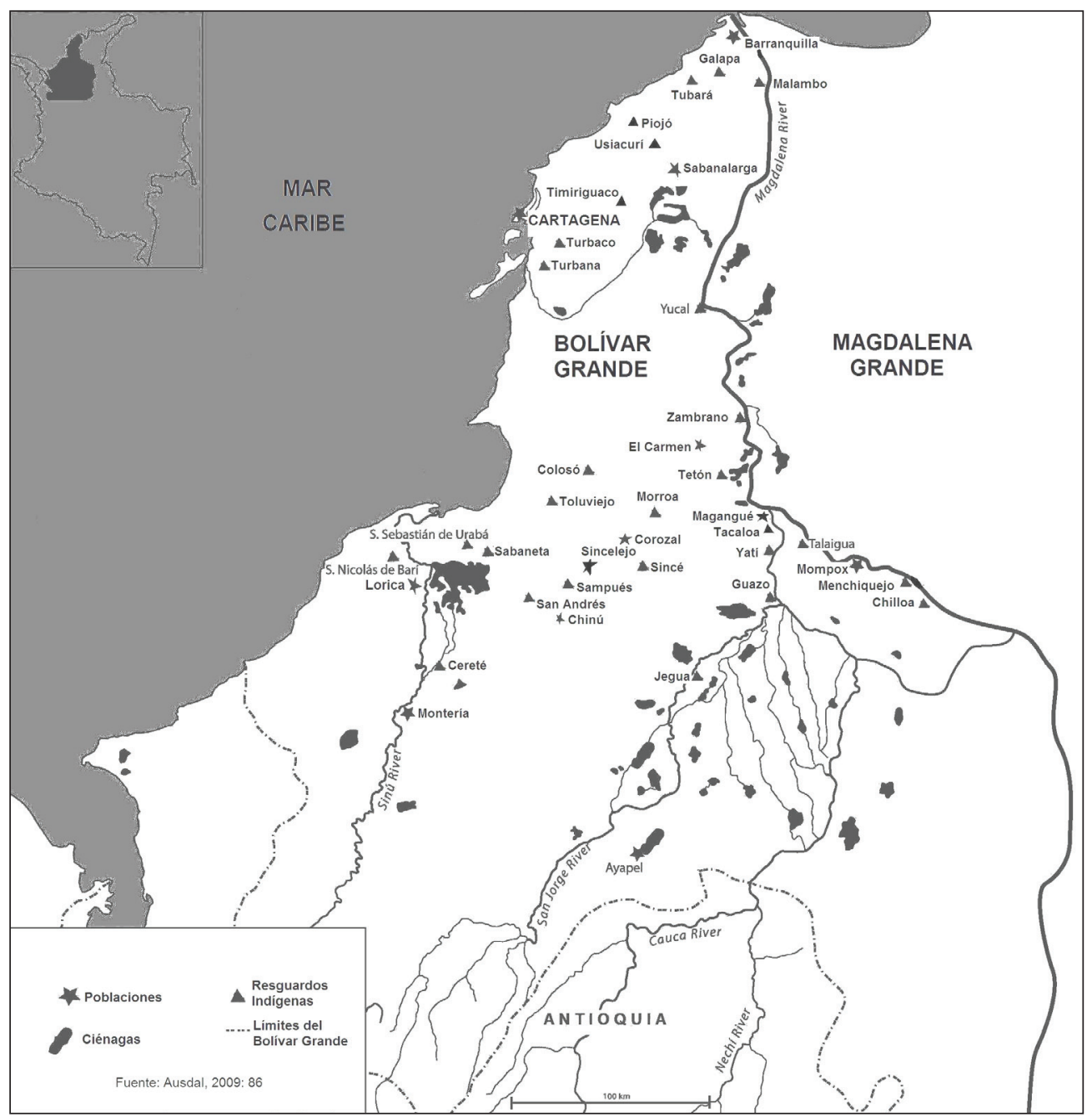

las definían como grupos étnicos (raza, cultura, genealogía, memoria social, relación con un espacio geográfico), para cohesionarse y diferenciarse de otras comunidades ${ }^{13}$.

Para el caso del Caribe colombiano, Steinar Saether es quien más ha avanzado en esta dirección gracias a sus estudios sobre los indios de la provincia de Santa Marta a finales del periodo colonial. Según este historiador la identidad indígena se definía desde lo racial, lo étnico-cultural y lo jurídico-político. Lo racial establecía diferencias fenotípicas con los no indios. Lo étnico-cultural definía a los indios por

13 Guarisco, 2004, p. 6. 
"su lugar de nacimiento, residencia, su indumentaria, estilo de peinado, por su dieta y ocasionalmente por su lengua y religión”. Y lo jurídico-político hacía de los indios un “... cuerpo político y jurídico específico dentro de la monarquía”, independientemente del detrimento de buena parte de sus características étnico-culturales ${ }^{14}$. Para las postrimerías de la Colonia era la última perspectiva la que tenía más peso en la definición de lo que era un indio, debido al avanzado proceso de mestizaje. Esta permitió seguir funcionado como un cuerpo político y jurídico dentro de la monarquía y la garantía de sus derechos políticos por el Estado colonial. El criterio que sustentaba esta relación de alteridad que permitía que las autoridades coloniales siguieran clasificándolos como indios era la genealogía, es decir, considerarlos como descendientes de los pueblos indios originarios ${ }^{15}$.

Según Saether, al ser la perspectiva jurídico-política la de mayor peso en la definición de las comunidades indias, con los cambios introducidos por la República en el ordenamiento político-territorial (la igualación de muchas de aquellas a la condición de las demás poblaciones) y con el otorgamiento de la ciudadanía, esa identidad perdió sentido. Explica este tránsito por los esfuerzos de las autoridades republicanas para integrarlos, desapareciendo la categoría de "indio" de los censos del siglo XIX, y desvaneciéndose las fronteras raciales ${ }^{16}$. En otros términos, Saether señala una renuncia a la indianidad por las comunidades de los alrededores de la ciudad de Santa Marta, y su reemplazo por la ciudadanía debido a la pérdida de relevancia de la primera en un contexto en el que la segunda definía la adscripción a la nación ${ }^{17}$.

Llama la atención el que Saether no se refiera a las tierras de los resguardos, ni a las actitudes de los indígenas frente a los ataques de los hacendados y de las poblaciones de los alrededores. Es como si esas comunidades que habían permanecido durante la segunda mitad del siglo XVIII en conflictos por asuntos de tierras con los hacendados y pobladores de los alrededores, y a las que se les había escriturado las tierras para esa época, para comienzos de la siguiente centuria renunciaron al único patrimonio que tenían, todo por llegar a ser considerados ciudadanos, parte de la República ${ }^{18}$. Se trata de una omisión nada desdeñable pues las investigaciones para otras regiones colombianas y latinoamericanas sobre las relaciones entre la identidad étnica, la tierra y la ciudadanía, muestran que durante el siglo XIX los indígenas supieron instrumentalizar el discurso republicano para defender sus intereses (tierras resguardadas y autonomía político-administrativa) ${ }^{19}$. Además, el mestizaje como ideología política tanto de la nación como del proceso de mestizaje, tampoco produjo tal supresión ${ }^{20}$.

Asimismo, no se puede pensar en las actitudes de los indígenas frente al discurso liberal y frente a la ciudadanía, sin tener en cuenta el tema de las tierras resguardadas,

14 SAEther, 2005a, pp. 61, 75-76, 79; 2005b, pp. 123-132.

15 SAETHER, 2005a, pp. 61-68.

16 Ibídem, p. 75.

17 Ibídem, pp. 61, 75-76, 79; 2005b, pp. 123-132.

18 "Los indios de Santa Marta... preveían que una república liberal basada en el principio de una supuesta igualdad de los ciudadanos ante la ley amenazaría a sus comunidades tanto en términos políticos como materiales". SAETHER, 2005a, pp. 69-71; 2005b; pp. 130-132, 71-72; GonZÁLEZ, 1993, pp. 102-106.

19 SANDERs, 2003, pp. 56-85; GuARISCO, 2004; Flórez, 2009, pp. 49-72.

20 Wade, 2007, pp. 379-402; Arias, 2005, pp. 94-112, 128-137; CASTro-GómeZ, 2005, pp. 66-88; LANGEBAEK, 2009, pp. 231-383. 
cuestión que adquirió cuerpo en la segunda mitad del siglo XVIII con el reconocimiento que hizo el Estado colonial sobre esas posesiones ${ }^{21}$, pero que alcanzó mayor dimensión durante la República, en especial de 1850 en adelante cuando se ensayaron producciones agropecuarias para los mercados internos ${ }^{22}$. No olvidemos que para los indígenas colombianos del siglo XIX las cuestiones relativas a la esfera del poder siempre estaban relacionadas con el espacio, con las formas de imponer el poder estatal en un espacio rural y en las decisiones sobre sus tierras.

\section{INDÍGENAS: TRIBUTO, FENOTIPO Y GENEALOGÍA}

En contra de las afirmaciones de Saether, la información procedente de los archivos y estudios recientes muestran que durante el siglo XIX la identidad indígena ocupó un lugar central en las discusiones políticas, constituyéndose en asunto crucial para muchos sectores de la población colombiana por las implicaciones que tenía en los proyectos de construcción de la nación, en el ordenamiento legal y en la distribución y jerarquía político-administrativa del territorio. Primero la abolición de la separación entre las repúblicas de blancos e indios, y la erección de muchos pueblos de estos últimos a la condición de distritos, no necesariamente conllevó a extinguir la identidad indígena. Segundo por el establecimiento de la ciudadanía. Tercero porque se acentuó el mestizaje, tanto como mezcla biológica y cultural, como por la construcción de una ideología interesada en hacer del resultado de esos cruces la base homogénea de la nación ${ }^{23}$. Y cuarto porque los indígenas instrumentalizaron el discurso republicano para defender sus intereses, construyendo varias identidades que ponían en escenas de acuerdo a los contextos e intereses en juego.

Estas circunstancias transformaron el lenguaje de la representación institucional de los distintos grupos socio-raciales, pues en términos formales la ubicación de cada uno con relación a la nación no podía darse con base en la discriminación como si sucedía en la Colonia. De ahí que para ponerle fin a la carga peyorativa que había acumulado el concepto colonial "indio", en la fase inicial de la República se acuñó el concepto "indígena", pero legislándose en unos términos que implicaron seguirlos considerando como personas sub-juris, merecedores de una normas proteccionistas por parte de las autoridades. En consecuencia, mientras que intentaban imponer la ciudadanía por encima de las identidades étnicas, se siguió considerando al indígena como incapaz por su propia condición racial, y merecedor del paternalismo de las autoridades hasta tanto perdiera esa condición, se convirtiera en ciudadano y en pequeño propietario de los lotes resultantes de la división de las tierras de los resguardos ${ }^{24}$.

21 GONZÁleZ, 1993, pp. 94-98.

22 Solano - Flórez, 2007a, pp. 92-117; 2007b, pp. 81-89.

23 Ibídem, pp. 41-57.

24 Martínez - Gallardo - Martínez, 2002, pp. 27-46. En el marco de las medidas adoptadas por las Cortes de Cádiz para poner fin a algunas expresiones de la atávica discriminación ejercida sobre la población indígena, en mayo de 1811 la Junta de Gobierno de la Provincia de Cartagena acordó estimular la residencia de foráneos entre los indios, estatuyendo la exoneración de pago de terraje a los libres que se casaran con indias. Edicto. Cartagena, 13-V-1811. El Argos Americano. BLAA. El liberalismo de los inicios de la República intentó integrar a los indígenas y les concedió el derecho al voto para elegir. Ver: Bando impreso dirigido a 
Estos factores contribuyeron a que la República mantuviera actitudes ambivalentes frente al indígena ${ }^{25}$, haciendo de su existencia tema de continuas discusiones al guardar una relación directa con la institucionalidad política que definía normas especiales que los regían, como también a una normatividad jurídica relacionada con una de las formas de propiedad territorial, el resguardo, que a su vez, estaba vinculada a la condición racial.

Fue un debate medular para las elites y otros sectores sociales que relacionaban esos asuntos con las condiciones raciales y morales de sus habitantes, y a éstas con las características del clima y de la geografía, con la herencia colonial y por último con los propósitos económicos agroexportadores ${ }^{26}$. La controversia articuló una diversidad de aspectos (ciudadanía, controles sociales, cuerpo, raza, mestizaje, salud, trabajo, enfermedad y la geografia), originando nuevas formas de concebir, ordenar, clasificar y jerarquizar la realidad social y natural, y marcando las relaciones entre los grupos de poder, los sectores subordinados y los espacios geográficos ${ }^{27}$.

Las medidas gubernamentales y las acciones emprendidas por los indígenas en el marco de la República, replantearon la condición de estos en varias direcciones. Se abolieron algunos de los elementos centrales que habían definido esa identidad bajo la dominación española, como era la separación entre los pueblos y ciudades, villas y parroquias de vecinos libres. La condición de súbdito (una de las bases del pacto colonial) fue reemplazada por la de ciudadano, dando paso a un discurso que reclamó la igualdad frente a la ley y en las contribuciones fiscales.

No obstante, diversos motivos como la debilidad del Estado, la inclinación por la causa realista de los indígenas en algunas áreas del Nuevo Reino de Granada (Pasto, Santa Marta, las sabanas centrales de la provincia de Cartagena y en el bajo curso del río Sinú) y las dificultades entre sectores de las elites para establecer un consenso hegemónico, llevaron a la República a mantener algunos elementos de la identidad institucionalizada. Se emitió una legislación de transición que los protegiera mientras se disolvían los resguardos y se distribuía las tierras en pequeñas propiedades, propósito que se fue aplazando por varias imposibilidades. También se conservaron los pequeños cabildos para administrar los bienes de la comunidad y para organizar diversas labores ${ }^{28}$. Asimismo, a diferencia de algunos países latinoamericanos ( $\mathrm{vgr}$. México), en Colombia se permitió que elevaran representaciones colectivas ante las autoridades ${ }^{29}$.

En consecuencia, durante el siglo XIX la identidad indígena estuvo sometida a una tensión debido a las continuas presiones ejercidas por distintos grupos para que a

todos los estantes y habitantes de la provincia de Cartagena por el presidente de la Junta de Cartagena, José María García Toledo, 9 de noviembre de 1810, en GutiérRez - MarTínez, 2008, pp. 78-85.

25 Esa ambivalencia se muestra en el uso dado por los criollos de la figura del indio como símbolo de la resistencia, convirtiendo el pasado de los nativos en una herramienta para deslegitimar la dominación colonial. Pero al tiempo que se reivindicaba el pasado precolombino se condenaba a los indígenas contemporáneos por considerarlos no apto para la civilización. LANGEBAEK, 2009, pp. 231-383; BOTERO, 2007, pp. 85-101.

26 Arias, 2005, pp. 94-112, 128-137; CASTRO-GómeZ, 2005, pp. 227-303.

27 Castro-Gómez, 2004, pp. 52-103.

28 Friede, 1976, pp. 103-104; Ordenanza XXIII (de 25 de octubre de 1852) Sobre resguardos de indígenas. Barranquilla, 9-XII-1852. La Regeneración de Sabanilla. Biblioteca Nacional de Colombia [en adelante BNC].

29 SANDERs, 2003, pp. 56-85; Guarisco, 2004; Flórez, 2009, pp. 64-72. 
los nativos solo se les reconociera la condición de ciudadanos, las ambivalencias de las políticas del Estado, y las diversas acciones emprendidas por los indígenas para conservar la condición étnica. Donde mejor se constata esa tensión es en las discusiones sobre las condiciones a tener en cuenta para establecer quiénes eran indígenas. Durante el último siglo de dominación colonial el tributo había servido para marcar una línea divisoria entre los indios y las demás personas de condición libre, lo que es igual a decir que fue un elemento central en la identidad imputada a los primeros ${ }^{30}$. Además, el pacto colonial entre el Rey y los indios súbditos implicaba que el tributo otorgaba a los segundos el derecho a usufructuar la tierra.

Por eso, los debates suscitados por el liberalismo gaditano en torno al tributo articularon temas como la ciudadanía, la igualdad, las necesidades fiscales del Estado y la identidad indígena. Este fue el caso de las discusiones efectuadas en las Cortes de Cádiz sobre la ciudadanía para los sectores americanos, en especial para los indios, aflorando el tema del tributo al considerarse que estaba en contravía con el principio de la igualdad en las cargas fiscales. La discusión fue planteada en los términos de las implicaciones de la ciudadanía en ciertas formas del pacto colonial que, como en el caso a que vengo refiriéndome, había permitido como contrapartida que la Monarquía española emitiera una legislación especial para los indígenas, concediéndoles un estatus jurídico-político que los había convertido en un cuerpo político dentro de la sociedad colonial. Aunque pudo existir acuerdo en los términos señalados, un sector de las Cortes de Cádiz y de las autoridades coloniales pensaba que era imposible abolir esa contribución fiscal por su alta representatividad porcentual en los ingresos del Estado colonial ${ }^{31}$.

Esas discusiones las heredaron las repúblicas latinoamericanas al tener que resolver problemas como la ubicación de los indígenas en la nación imaginada, la cobertura de la ciudadanía, la estructura administrativa de los Estados y sus necesidades fiscales, y las formas de propiedad de bienes inmuebles. En especial porque la condición de tributario presente o por ascendencia fue central para determinar las políticas del Estado frente a las tierras de los resguardos. Las decisiones normativas siguieron cursos distintos acorde con las particularidades de las regiones y de los distintos países. En algunos lugares se logró abolir el tributo como fue el caso de México ${ }^{32}$. En otros fue rápidamente restablecido como sucedió en Perú y Ecuador ${ }^{33}$. En otros sitios fue sometido a una renegociación por el interés mostrado por los indígenas en mantenerlo como condición para que se les siguiera reconociendo un estatus especial, como sucedió en Bolivia, donde los indígenas lucharon por mantener el tributo para conservar sus propiedades colectivas ${ }^{34}$.

Ahora bien, la fragmentaria información de archivos no permite conocer con alguna certeza los avatares sufridos por el tributo en las distintas regiones colombianas donde existían indígenas. Considerado como una carga onerosa que había favorecido

30 Gutiérrez, 2007, pp. 117-128.

31 EsCOBAR, 2010, pp. 43-45.

32 Ibídem, p. 50.

33 GuARISCO, 1995.

34 Ibídem; Escobar, 2010, pp. 41-57; Mendieta, 2005, pp. 131-154; IruRozqui, 1999, pp. 705-740; 2006, pp. 35-66; Soux, 2008, pp. 18-48. 
a los corregidores y a los curas doctrineros ${ }^{35}$, la Junta de Gobierno de Cartagena de Indias lo suprimió en mayo de 1811 siguiendo los dictámenes de las Cortes de Cádiz. Luego fue restablecido por la reconquista española de $1815^{36}$.

Consolidada la República lo que siguió fue una serie de ambivalencias. La legislación de los años 1830 lo reemplazó por la llamada contribución personal indígena ${ }^{37}$, y normas legales del decenio siguiente lo restablecieron. Años después, cuando el Estado se propuso repartir las tierras de los resguardos entre los indígenas, se consideró que la categoría de tributario era la única que permitía establecer una línea divisoria entre indígenas y las demás personas de otras condiciones étnicas avecindadas en las poblaciones de aquellos ${ }^{38}$. Normas de los años 1850 consagraron que esa condición podía ser presente o por ascendencia genealógica. En 1852 la Cámara de la provincia de Sabanilla (actual departamento del Atlántico), con base en la ley de 22 de junio de 1850 expidió la ordenanza XXIII "Sobre resguardos de indígenas". Esta norma, que tenía como propósito repartir sus tierras, obligaba a los pequeños cabildos a levantar un censo de las familias de esa condición teniendo en cuenta los siguientes criterios:

$1^{\circ}$ - Los indígenas tributarios y sus familias, aunque sus mujeres sean vecinas [es decir, no indígenas].

$2^{\circ}$ - Los indígenas que no hayan pagado tributo, y cuyo padre fue tributario.

$3^{\circ}$ - Las indígenas solteras que tengan hijos, y estos mismos hijos, siempre que aquellas sean hijas de tributario o naturales de soltera.

$4^{\circ}$ - Las indígenas casadas con vecinos, siempre que sean hijas de tributario o naturales de soltera, y los hijos que hubieren tenido estando solteras.

$5^{\circ}$ - Los indígenas que no hayan tributado por haber obtenido los empleos del cabildo de indígenas ${ }^{39}$.

Sin embargo, en términos de los indígenas el tributo era cosa del pasado. En 1867 los procuradores de los distritos de Usiacurí y Piojó que tenían funciones protectoras sobre los resguardos, protocolizaron en la notaría de Sabanalarga unos documentos judiciales que contenían declaraciones de personas notables sobre las poblaciones de

35 Visita de la encomienda de Tubará, propiedad de Francisco de Ledesma por Lope de Ceballos Barreda, Cartagena, 13-V-1811, Visitas, Gobernación de Cartagena, 1660-1673, №. 2. Archivo General de Indias. Escribanía 644"; Edicto, El Argos Americano, folios. 6-267, BLAA.

36 CUÑo, 2008, pp. 202, 256.

37 Leyes de la primera mitad del siglo XIX sobre los indígenas: Lei 1. Octubre 11 de 1821. Sobre la abolicion del tributo, i repartimiento de los resguardos de indíjenas; Lei 2.- Marzo 6 de 1832. Sobre repartimiento de los resguardos de indígenas, y Lei 3. Junio 2 de 1834. Adicional a las leyes sobre repartimiento de los resguardos de indígenas, en Pomвo, 1845, pp. 100-103. También ver el Decreto de 1820 (mayo 20) que ordena devolver a los naturales los resguardos, en RoLDÁn, 1990, pp. 11-25.

38 Lei 3. Junio 2 de 1834 . Adicional a las leyes sobre repartimiento de los resguardos de indígenas, en Pомво, 1845, pp. 101-102. En especial ver el parágrafo único del artículo $3^{\circ}$.

39 Ordenanza XXIII (de 25 de octubre de 1852) Sobre resguardos de indígenas. Barranquilla, 9-XII- 1852. La Regeneración de Sabanilla. BNC. El propósito de esta norma era facilitar la repartición de las tierras de los resguardos, lo que al parecer tuvo acogida entre algunos sectores que, como en caso del resguardo de Galapa otorgaron poder a abogados para que adelantaran las diligencias pertinentes. Poder especial. Remigio de la Hoz a favor de José Gravier, apoderado de los indígenas de Galapa, 31-I-1854, Archivo Histórico del Departamento del Atlántico [en adelante AHDA]. Fondo notarial, Sección $1^{\mathrm{a}}$, Notaria Primera de Barranquilla, Libro de 1854, escritura $\mathrm{N}^{\mathrm{o}}$. 38, fols. 44v.-45v. Poder especial. Varios vecinos del resguardo indígena de Galapa, a favor de José Gravier, 21-I-1859, AHDA, Libro de 1859, escritura No. 14, fols. 15-17. 
indígenas homónimas. Lo importante de esas declaraciones para el punto que estamos dilucidando fue que los testigos dieron fe sobre temas referidos a:

1) Las relaciones entre las comunidades indígenas con las poblaciones circunvecinas;

2) Si las características físicas de los habitantes de Usiacurí y Piojó eran indígenas; 3 )

Si se reconocía desde mucho tiempo atrás que esas poblaciones eran indígenas;

4) Si los habitantes de Usiacurí y Piojó habían sido tributarios del Rey de España;

5) si habían mantenido el pequeño cabildo, y

6) si el arriendo de tierras a personas no indígenas lo llevaban a cabo siguiendo los procedimientos de las costumbres indígenas ${ }^{40}$.

En las declaraciones no se adujo el tributo como una condición presente ${ }^{41}$.

Las dificultades para reconocer a la población indígena del país a partir del tributo llevaron a algunas legislaciones regionales como la del Gran Cauca ${ }^{42}$ y la del Bolívar Grande a establecer criterios de identidad como el fenotipo y la genealogía ligada a ascendientes que hubieran sido tributarios. Es decir, la condición de tributario se convirtió en una característica de los antecesores que servía para indicar que se descendía de indígenas ${ }^{43}$. Estas disposiciones originaron enfrentamientos entre distintas vertientes políticas de inspiración liberal en torno a las relaciones entre la ciudadanía, la identidad étnica y ciertos derechos devenidos de esta última. La discusión tocaba de manera directa a los indígenas en la medida en que la condición de ciudadano podía utilizarse para negar su existencia y/o para demandar de las autoridades la supresión de cualquier normatividad que los protegiera por encima del resto de los habitantes ${ }^{44}$. Pero también podía emplearse en sentido contrario por los indígenas, para defender sus derechos ${ }^{45}$.

40 Protocolización de una diligencia que acredita la propiedad de los Indíjenas del pueblo de Usiacurí, AHDA, sección $1^{\mathrm{a}}$, fondo notarial: Notaria Única del Circuito de Sabanalarga, Libro de 1867-1869, tomo único, escritura $\mathrm{N}^{\circ} .16$ fols. 1v-13r,,Protocolización de unas diligencias que acredita la propiedad de los indíjenas de Piojó, sobre los terrenos de su respetivos resguardos, AHDA, Notaria de Sabanalarga, Libro de 1867-1869, escritura $\mathrm{N}^{\circ} .12$, folios 20v-26r.

41 Consulta del gobernador de la provincia de Nieto, de varios puntos de la ley de 31 de julio último sobre administración de los resguardos de indígenas e Informe del gobernador de la provincia de Nieto. Cartagena, 20/27-III-1864, Gaceta Oficial del Estado Soberano de Bolivar, BLAA.

42 En el Estado del Cauca la raza era un término impreciso que además de los factores señalados contemplaba otros elementos como la cultura, clase, idioma, historia y geografía. SANDERS, 2003, p. 59. Según Appelbaum, la ley 90 de 1859 de ese Estado solo definió al indígena en función de los derechos de la propiedad territorial basados a la vez en una genealogía que estuviera ligada a ascendientes que hubieran pagado tributo. Appelbaum, 2007, p. 136.

43 El Estado del Cauca bajo la presidencia de Tomás C. de Mosquera expidió la ley 90 de 1859 (Sobre protección de indígenas), convertida en el formato de buena parte de la legislación del Estado de Bolívar bajo la administración de Juan José Nieto, y luego en el fundamento de la ley 89 de 1890, la que en parte aún sigue rigiendo a los resguardos indígenas. SANDERS, 2004, pp. 18-99, 125-183.

44 En la base de esa ambivalencia que originó corrientes abolicionistas y conservacionistas de los resguardos, estaba una imagen del indígena como un ser incapaz de insertarse por sus propios medios y de manera satisfactoria en el proyecto civilizador de la época. SAFFORD, 1991, pp. 1-33.

45 SANDERs, 2003a, pp. 56-85; Flórez, 2009, pp. 64-72. 
Hubo un sector liberal que por razones doctrinales y de conveniencia política ${ }^{46}$ prefirió, por encima de las normas constitucionales que consagraban la igualdad, la propiedad individual y la libre circulación de la tierra, proteger los derechos de los indígenas. Por un lado este liberalismo basaba su acción gubernamental en la política del bien común, concibiendo la función del gobierno como un punto de equilibrio entre los distintos sectores de la sociedad y como la protección de ciertos derechos de los sectores más débiles. Pero razones de interés político también intervinieron. Desde 1863 Juan José Nieto, presidente del Estado de Bolívar, empezó a afrontar la oposición de sectores de comerciantes de las provincia de El Carmen, Lorica y Barranquilla, por las medidas que tomó para destinar buena parte de los recursos del Estado para mejorar la navegación por el Canal del Dique que unía a Cartagena con el cauce principal del río Magdalena, a la altura del puerto fluvial de Calamar, en detrimento de la vía del tabaco que se exportaba por Barranquilla ${ }^{47}$.

Como muchos de estos comerciantes eran también hacendados ganaderos que tenían problemas con los indígenas por motivo de las tierras resguardadas, Nieto emitió una legislación protectora para ganarse el apoyo de los últimos. A comienzos de 1863 , solicitó a los gobernadores provinciales recabar informes detallados sobre los resguardos existentes en las áreas bajo sus jurisdicciones, censar a los indígenas especificando edades, estado civil, tributarios, a los no indígenas que vivían dentro de los términos de los resguardos, sus cultivos, crías, casas y administración del tributo. Con esta información se buscaba,

poner remedio a los abusos que se cometen en los resguardos de indígenas y de arreglar la administración de estos y la inversión de sus productos de una manera conveniente a los sagrados títulos con que los poseen aquella clase de la sociedad ${ }^{48}$.

Meses más tarde la Asamblea Legislativa del Estado Soberano de Bolívar emitió una ley que ofreció parecida solución para saber quieres eran indígenas. El centro de esta ley era la reconstrucción de las genealogías, es decir, demostrar que los ascendientes de las personas catalogadas como tal poseían esa condición ${ }^{49}$. Se trataba de una solución sencilla y de uso corriente, pues la lectura de la condición étnica de las personas partía de reconocer los rasgos físicos. Esta ley insistió en la necesidad de empadronar a las familias de los nativos con derecho a los resguardos, a protocolizar los títulos de propiedad o a reconstruirlos donde no existieran, a averiguar sobre los terrenos usurpados a los resguardos, declarando nulo cualquier contrato que los

46 La guerra civil de 1859-1861 contra el gobierno conservador de Mariano Ospina Rodríguez originó un interés en ganar el apoyo de la población indígena. En el Gran Cauca los indígenas se inclinaron por un conservadurismo popular con el objeto de preservar los resguardos de los ataques de los liberales quienes los consideraban una rémora de privilegios especiales reñidos con la igualdad jurídica. Los indígenas deseaban ser ciudadanos de una República que respetara sus tierras originarias y su organización autónoma. Su apoyo al partido Conservador surgía de su respeto a la comunidad, la autoridad patriarcal y la religión. SANDERS, 2004b, pp. 18-99 y $125-183$.

47 FALS, 1986, pp.164-167.

48 Circular pidiendo ciertos datos sobre resguardos indígenas. Cartagena, 8-III-1863, Gaceta Oficial del Estado Soberano de Bolívar, BLAA.

49 Ausdal, 2009, pp. 94-105. 
menoscabara, establecía el valor del arrendamiento de las tierras y nombraba como representante de los indígenas al Procurador General del Estado ${ }^{50}$.

En el marco de esta ley el Poder Ejecutivo dispuso que los alcaldes distritales adelantaran censos de las poblaciones indígenas situadas en sus jurisdicciones, incluyendo a los que vivieran en otros lugares. Para esto último se aconsejó acudir a los indios más ancianos y honrados. El censo pretendía establecer la existencia o no de indígenas, para así poder disponer de los terrenos donde los nativos hubiesen desaparecidos. Respecto a la posesión y propiedad de las tierras de los resguardos el decreto ejecutivo dispuso ratificar que era propiedad de los indios las tierras otorgadas por la Corona Española. El decreto también consagró que los resguardos podían tener una extensión mayor a la estipulada en las leyes de Indias (una legua castellana). Asimismo señaló que los alcaldes distritales debían recoger información sobre los títulos de propiedad, informaciones al respecto, sentencias judiciales, diligencias de posesión para remitirlas a las notarías. En caso de que los títulos no existieran debía nombrarse un agrimensor, quien a partir de las informaciones de los ancianos hiciera la mesura para establecer la propiedad con base en las leyes de Indias. Decretó que los terrenos de los resguardos eran inalienables e imprescriptibles, y que se

tendrán por nulos, de ningún valor ni efecto todos los títulos, contratos, escrituras y demás documentos, públicos o privados, de cualquier naturaleza que sean, en cuanto cercenen o menos caben la posesión legal o libre uso de los resguardos, en cuya posesión quedan los interesados restituidos Ipso jure desde la publicación del presente decreto $^{51}$.

Cualquier duda para determinar quiénes eran indígenas, debía solucionarse recabando pruebas y testigos con ayuda de la tradición oral. En el caso de posibles litigios

50 Ley sobre administración y aplicación del producto de los resguardos de indígenas. Cartagena, 9-VIII1863. Gaceta Oficial del Estado Soberano de Bolivar, BLAA. Sumado a la genealogía y el fenotipo intervenían otros factores para establecer esa condición como era el caso de la geografía, el lugar de origen caracterizado a lo largo de la historia como zona de poblamiento indígena. También ayudaba, como en el caso de Tubará, la existencia de yacimientos arqueológicos a flor de tierra, y las expresiones culturales tales como el trabajo de artesanías con el algodón, al que se le reconocía un largo ancestro precolombino. NIETo, 1993, p. 173. Todos estos elementos se combinaban de distintas maneras en el imaginario común y corriente de la época para definir los atributos étnicos de las personas. Como se trataba de indígenas reducidos desde la temprana colonia, que habían perdido el idioma, buena parte de las creencias religiosas y sus formas de organización social y política, para las gentes de los alrededores la caracterización étnica de aquellos no estaba en función de los elementos perdidos.

51 Decreto de 10 de octubre de 1863, sobre administración y aplicación del producto de los resguardos de indígenas. Cartagena, 11-X-1863. Gaceta Oficial del Estado Soberano de Bolívar, BLAA. El año siguiente se llevaron a cabo las diligencias de deslinde de los resguardos de Toluviejo, Colosó, San Nicolás de Bari (ver mapa 1). Extracto del título supletorio de los terrenos de los indígenas del distrito de Toluviejo que se publica de conformidad con el artículo $7^{\circ}$ del Decreto de 10 de octubre de 1863, y Extracto del título supletorio de los terrenos de los indígenas del distrito de Colosó. Cartagena, 6-III-1864; Extracto del título supletorio de los terrenos de los indígenas del distrito de San Nicolás de Bari. Cartagena, 1-V-1864. Gaceta Oficial del Estado Soberano de Bolivar, BLAA. Piojó y Usiacurí protocolizaron los títulos de las tierras de sus resguardos en 1868. Índice cronológico, Notaría de la provincia de Sabanalarga, 1868. Cartagena, 13-VI-1869; San Andrés de Sotavento lo hizo en 1870. Copia del índice cronológico Notaría de la Provincia de Chinú, año de 1870. Cartagena, 13-I-1871. Gaceta de Bolivar, BLAA. 
al delimitar los términos de los resguardos, las autoridades fueron tajantes en el propósito de reponer los linderos originales:

Aunque los indígenas tengan alguna posesión judicial de sus terrenos, si esa no es toda la porción que les pertenece, los gobernadores deben cumplir con lo prevenido en el artículo $8^{\circ}$ del citado decreto, sin tener para qué tocar con el personero o el fiscal, pues no se trata de un procedimiento judicial, sino gubernativo ${ }^{52}$.

Para otro sector del liberalismo del Bolívar Grande las identidades distintas a la ciudadanía, como era el caso de la indígena, implicaban privilegios que estaban en contravía con el principio de la igualdad, al generar derechos como el de tener tierras resguardadas, cobrar terraje a otros que utilizaran esas tierras y una protección por parte de las leyes que los diferenciaban del resto de la población. Además, sostenía que la propiedad colectiva sobre las tierras contravenía el principio constitucional de la propiedad individual y la libre circulación comercial de los bienes inmuebles ${ }^{53}$. Para los años de 1860 los abolicionistas habían rechazado los criterios del fenotipo, la genealogía y la autoidentificación para determinar quiénes eran indígenas, considerando que el mestizaje había avanzado a tal grado que era imposible determinar con certeza quienes poseían esa condición étnica ${ }^{54}$, e insistieron más en los aspectos de la cultura aborigen perdida para negar la existencia de aquellos, como también en la supuesta ilegalidad de las normas coloniales que dieron origen a los resguardos.

En 1864 el juez de la recién creada provincia de Nieto en la que estaba situado el resguardo de Cereté, objetó el trabajo de censar a los indígenas, considerando que un

52 Resolución. Cartagena, 20-III-1864. Gaceta Oficial del Estado Soberano de Bolívar, BLAA.

53 Informe del gobernador de la provincia de Nieto. Cartagena, 27-III-1864; Informe del gobernador de la provincia de Sabanalarga. Cartagena, 10-IV-1864; Informe del gobernador de la provincia de Lorica, e Informe del gobernador de la provincia de Barranquilla. Cartagena, 22-V-1864. Gaceta Oficial del Estado Soberano de Bolivar, BLAA. Esa norma constitucional de 1863 para los Estados Unidos de Colombia, también fue consagrada por la constitución del Estado de Bolívar de ese año, la que en sus artículos 81 a 83 prohibía que la iglesia se convirtiera en propietaria, y cualquier forma de vínculo sobre la propiedad territorial que la sacara de la circulación comercial. Constitución política del Estado. Cartagena, 12-VII-1863. Gaceta Oficial del Estado Soberano de Bolivar, BLAA. Dos años después, una nueva constitución del Estado de Bolívar estipuló parecidas normas. COMPILACIÓN DE LEYES, 1876, pp. xx y xxv.

54 Esa tensión se pronunció por nuevos elementos surgidos a lo largo de la primera centuria republicana. Los contrastes entre los indígenas reducidos desde tiempos coloniales y los indígenas "salvajes", fueron inevitables pues desde la segunda mitad del siglo XIX los procesos de colonización de las tierras calientes obligaron a pensar el territorio y sus habitantes y a construir interpretaciones sobre extensas áreas del país controladas por la segunda clase de indígenas. LANGEBAEK, 2009, pp. 246-251, 265-271. Al convertirse en un punto de comparación, los interesados en las tierras de los resguardos demandaron que las autoridades identificaran a los indígenas con la condición mestiza, y, por tanto, que abolieran cualquier legislación que los protegiera. Por eso, mientras que sobre los "salvajes" se legisló para buscar la forma de reducirlos, frente a los que desde la Colonia habían avanzado en su integración a la sociedad mayor la legislación guardó una dualidad entre su protección hasta que se transformaran en pequeños campesinos propietarios, y así lograr abolir cualquier forma de vida basada en la condición étnica. ARIZA, 2009, pp. 202-212. En la Geografía de T. C. de Mosquera la población indígena aparece reducida a la no sometida por parte de las autoridades, calculando, para el caso de Bolívar, 2000 indios que no habían sido reducidos. MosquerA, 1866, p. 121. 
padrón elaborado con base en la información proporcionada por estos carecía de objetividad $^{55}$. Al final se mostraba partidario de disolver los resguardos en razón de que:

1) establecían distinciones raciales que eran contrarias a los principios de la constitución y de las leyes.

2) representaban un privilegio tanto por los beneficios que recibían los indígenas, como porque les permitía imponer a los extraños a las comunidades radicados en sus tierras unas cargas impositivas que hacían de los individuos a ellas sujetos, “... de peor condición que los demás".

3) como forma de propiedad comunitaria y proindivisa violaban la norma constitucional que rezaba, “... la propiedad raíz no puede adquirirse con otro carácter que el de enajenable y divisible a voluntad exclusiva del propietario...", y también porque estaba en contradicción con las normas que prohibían sustraer la propiedad raíz de la libre circulación comercial, y que era un "contrasentido en el actual progreso".

4) era anticonstitucional el privilegio de los resguardos porque la mayoría de sus habitantes no eran indígenas y tenían que pagar impuestos a éstos.

5) el recaudo de los tributos y del impuesto de terraje era motivo de "intrigas, vejaciones y extorsiones".

6) las cargas fiscales producirían la migración de los no indios.

Luego concluía que,

Por todo lo expuesto opino que la ley debe suprimir los resguardos, concediendo a todos los distritos un ejido para sus crías y labores más o menos grande según la población, donde todos puedan trabajar sin ningún gravamen ${ }^{56}$.

En este tipo de razonamientos coincidían buena parte de los hacendados y políticos de la región. El gobernador de la provincia de Sabanalarga, en la que estaban situados los resguardos de Piojo y Usiacurí, también informaba sobre las dificultades en la aplicación de la mencionada ley, dando como solución,

acabar de una vez con los mentados privilegios de los indios, porque... los indios eran y creo que son y serán siempre robados, por la misma razón de ser indios. La ley debía declarar propiedad de los distritos los terrenos denominados resguardos de indígenas y disponer que los Concejos no pudieran imponer ninguna contribución a los indígenas que trabajaran en los terrenos cedidos ${ }^{57}$.

El gobernador de la provincia de Lorica, que contenía a los indígenas de San Andrés de Sotavento, señalaba que habiendo estos

55 Consulta del gobernador de la provincia de Nieto, de varios puntos de la ley de 31 de julio último sobre administración de los resguardos de indígenas y Registro que lleva el juez de la provincia de Nieto, de los vacíos e inconvenientes que en su concepto presentan las leyes y decretos del Estado. Cartagena, 13/20-III 1864. Gaceta Oficial del Estado Soberano de Bolívar, BLAA.

56 Informe del gobernador de la provincia de Nieto. Cartagena, 27-III-1864. Gaceta Oficial del Estado Soberano de Bolivar, BLAA. (Cursivas en el texto original).

57 Informe del Gobernador de la Provincia de Sabanalarga. Cartagena, 10-IV-1864. Gaceta Oficial del Estado Soberano de Bolívar, BLAA. 
desde la Independencia del país adquirido iguales derechos a los demás granadinos, han debido perder el privilegio que los reyes de España les concedieron ${ }^{58}$.

Manuel Ezequiel Corrales, gobernador de la provincia de Barranquilla, informaba que estaba enterado "que la generalidad mira con repugnancia dicha ley por varias causas":

1) Al mezclarse los indígenas era difícil averiguar y censar a los verdaderos indígenas y se juzgaba, por consiguiente, que ha caducado el derecho que tenían a los resguardos de tierras, a no ser que se conceda a todos los que componen el vecindario.

2) Otros consideran injusta la conservación del derecho que se da a los indígenas sobre los resguardos, si él tiene por fundamento el pago de los tributos y de la contribución personal que ingresaban al erario público conforme a las leyes de Indias y al decreto del Libertador Simón Bolívar de 15 de octubre de 1828, porque todos los asociados tuvieron y tienen el deber de contribuir para los gastos públicos, sin otra compensación que la de gozar individualmente de las garantías constitucionales.

3) El resguardo tuvo su razón de ser en la Colonia por las políticas de reducción y concentración de los indios en pueblos para evitar la dispersión. Con ese motivo se les asignó ejidos para cría y labor, buscando que no se salieran de sus reducciones, al tiempo que se prohibió que quienes no fueran indígenas se avecindaran en los territorios de los nativos, de suerte que con semejante aislamiento o concentración hubo necesidad de proveerlos de terrenos suficientes para evitar la comunicación con las otras razas.

4) Ahora no existen tales prohibiciones. Los que tienen descendencia de indios gozan de libertad para establecerse y trabajar donde quieran, y esto indica que esas cuestiones de resguardos deben terminar, así como ha sido casi extinguida aquella raza, con el constante y sucesivo trato con las demás ${ }^{59}$.

Después de la caída de Nieto, en 1864 ascendió al poder del Estado de Bolívar el grupo liberal dirigido por Ramón Santo Domingo Vila y los hermanos González Carazo, representantes de los emergentes sectores de hacendados interesados en derogar la legislación protectora de los indígenas ${ }^{60}$. Durante la segunda mitad del decenio de 1860 se acentuó la desprotección de éstos por parte de las autoridades bajo el argumento que no se podía brindar amparo por vía ejecutiva, pues el derecho de igualdad que consagraba la constitución de 1863 consideraba ilegal, "conceder privilegios o distinciones legales que cedan en puro favor o beneficio de los agraciados, y que por

58 Informe del gobernador de la provincia de Lorica. Cartagena, 22-V-1864. Gaceta Oficial del Estado Soberano de Bolivar, BLAA.

59 Informe del gobernador de la provincia de Barranquilla. Cartagena, 22-V-1864. Gaceta Oficial del Estado Soberano de Bolivar, BLAA.

60 Solano - Flórez - MALKún, 2010, pp. 15-42. Información sobre iniciativas legislativas para abolir los resguardos o para que sus tierras fueran administradas por los distritos en que estaban ubicados: Ver Asamblea Legislativa del Estado. Sesión del día 9 de octubre de 1867. Cartagena, 3-XI-1867; Memorial de varios vecinos del extinguido distrito de Malambo y resolución. Cartagena, 28-I-1869; Administración de justicia. Autos. Cartagena, 15-V-1870; Asamblea Legislativa, Proyecto de ley sobre administración de los resguardos indígenas. Cartagena, 5 y 8-X-1871; Poder Ejecutivo del Estado. Decretos. Cartagena, 15VIII-1873; Representación de varios indígenas de Toluviejo y resolución. Cartagena, 20-IX-1873. Gaceta de Bolivar, BLAA; Proyecto de ley que manda repartir los resguardos de indígenas. Cartagena, 19-X-1875; Proyecto de ley sobre resguardos indígenas e Informe de la comisión. Cartagena, 2-X-1877; Cartagena 22-VII1884. Diario de Bolivar, BLAA; Informe del gobernador de la provincia de Sincelejo. Cartagena, 10-IX-1894. Registro de Bolivar, BLAA. 
consiguiente los indígenas quedan equiparados a los demás habitantes del Estado y sin derecho por consiguiente a la protección especial que las leyes anteriores les acordaron" ${ }^{61}$.

La ciudadanía y la igualdad se constituyeron en los argumentos centrales para desconocer la existencia de los derechos de los indígenas ${ }^{62}$. Desde la igualdad se atacó la legislación sobre resguardo por considerar que estimulaba la división de la sociedad en razas ${ }^{63}$. Esos ataques también se hicieron desde la ideología del mestizaje que permitía afirmar que los indígenas se habían mezclado y desaparecido, como sucedió con el caso del resguardo de Tubará, declarado bien vacante en 1886 por las autoridades judiciales de Barranquilla bajo ese argumento ${ }^{64}$. En 1899 el apoderado del distrito de Soledad en juicio contra los indígenas de Malambo para lograr que se declarara bien vacante las tierras de ese resguardo, nuevamente aducía que era imposible determinar quiénes eran descendientes de indígenas ${ }^{65}$.

\section{REFLEXIÓN FINAL}

En el marco de esas discusiones y legislación oficial, los indígenas diseñaron diversos recursos para defender su condición y el derecho a la tierra. Entre los medios de defensa resaltan el argumento de la no incompatibilidad entre la identidad política de la ciudadanía con la condición étnica, el reflejo de esta condición en el fenotipo, el lugar de residencia, la genealogía, las relaciones de alteridades, y el deber de la República de protegerlos ${ }^{66}$. Frente a los intentos de declarar ilegal cualquier disposición emanada del Estado colonial ${ }^{67}$, basaron sus peticiones en la legislación republicana,

61 Memorial del señor Victoriano Peña solicitando se ampare a los indígenas de Toluviejo en la posesión de su resguardo. Cartagena, 20-VI-1869. Gaceta de Bolívar, BLAA. También ver: Representación del señor Luís José Gaviria para que no se establezcan otros pajares en el distrito de San Andrés. Cartagena, 27-VI-1869. Gaceta de Bolivar, BLAA; Informe del gobernador de Sincelejo. Cartagena, 9-VIII-1875. Diario de Bolívar, BLAA; Memorial de varios vecinos del distrito de Montería, solicitando la protección del gobierno contra varios ataques a sus ganados. Cartagena, 25-VII-1869; Memorial de varios vecinos del extinguido distrito de Malambo y resolución. Cartagena, 28-I-1869, Gaceta de Bolivar, BLAA.

62 Administración de Justicia. Acuerdos. Cartagena, 17-III-1867; Administración de Justicia. Juzgado de la provincia de Sincelejo. Cartagena, 20-X-1867; Administración de Justicia. Cartagena, 7-VI-1868; Memorial de varios vecinos del extinguido distrito de Malambo y resolución, Cartagena, 28-I-1869; Denuncio dado por el Señor Felipe B. Sampayo de unos terrenos baldíos. Cartagena, 6-VI-1869; Memorial del Señor Victoriano Peña solicitando se ampare a los indígenas de Toluviejo en la posesión de su resguardo. Cartagena, 20-VI1869; Representación del Señor Luís José Gaviria para que no se establezcan otros parajes en el distrito de San Andrés. Cartagena, 27-VI-1869; Administración de Justicia. Autos. Diligencias criminales. Cartagena, 15-V-1870. Gaceta de Bolivar, BLAA.

63 Informe del gobernador de la provincia de Nieto. Cartagena, 27-III-1864. Gaceta Oficial del Estado Soberano de Bolivar, BLAA.

64 Solano - Flórez, 2007b, pp. 81-89.

65 Manotas, 1899, p. 8.

66 Diligencia de apeo del resguardo de indígenas de Malambo. AHDA, Sección 1, Notaria Primera de Barranquilla, Libro 1838-1839, tomo único, folios 144r-207r.; Diligencia de deslinde i posesion de tierra correspondiente a los naturales de Galapa i Paluato [1837]. AHDA, Notaria Segunda, Libro de 1944, tomo 2, folios $4208 \mathrm{r}-4214 \mathrm{v}$.

67 El gobernador de la provincia de Lorica, desde la lógica jurídica pensaba que al igual que se protegía las formas de propiedad individual que emanaban de títulos otorgados por la Corona "¿con qué fundamento, 
en especial en la Recopilación Granadina a la que erigieron en la norma fundacional de sus derechos ${ }^{68}$.

Así emplearon la historia de acuerdo con sus intereses. El pasado colonial se convirtió en un referente para medir los tratos recibidos bajo la República. Los indígenas de Toluviejo reclamaban la protección de las autoridades para evitar los vejámenes a que eran sometidos por ganaderos de Sincelejo, recordándoles a las autoridades del Estado de Bolívar que,

los conquistadores reconocieron nuestra propiedad en el espacio de terreno que nos asignaron como resguardo, y dieron leyes para mantenernos en la propiedad de ellos, y para defendernos en su posesión. El redentor gobierno de Colombia hizo lo mismo... poniéndonos a cubierto con su protección contra los ataques del poder de las riquezas y de la ambición ${ }^{69}$.

Y el pasado inmediato, en concreto la lucha por la Independencia, se constituyó en un referente para reclamar una posición en la nación acorde con sus contribuciones. Así en una sucinta pero dramática narración diseñada para evitar pasar a la condición de agregación del distrito de Soledad, los indígenas del resguardo de Malambo recordaban a las autoridades del Estado de Bolívar que Malambo era un antiguo asentamiento prehispánico con cuyos habitantes siempre contó Cartagena cuando fue asediada por corsarios ingleses, franceses y holandeses. Que esos sacrificios, más su conversión al cristianismo fue lo que llevó al Rey español a concederles las tierras resguardadas. También rememoraban a las autoridades centrales radicadas en Cartagena pudo resistir más de cien días al ejército reconquistador español dirigido por Pablo Murillo, gracias a que aquellos lo retuvieron durante varios días, costándoles el incendio total del pueblo y la muerte de centenares de indígenas ${ }^{70}$.

Los indígenas jugaron con diversas identidades (indígenas, mestizos y ciudadanos) en concordancia con sus intereses, apropiándose los elementos del discurso liberal republicano que les permitían retroalimentar sus puntos de vista sobre los problemas que los aquejaban, en especial en sus relaciones con otros sectores sociales, los partidos políticos y las autoridades. Y el uso de las distintas identidades en ciertas circunstancias fue un arma eficaz para la defensa de sus intereses, pues cuando la negación de esa condición racial fue el argumento esgrimido por los interesados en echar mano de las tierras de los resguardos, los indígenas actuaban en varios planos, y buscaban alianzas con sectores políticos para resistir las arremetidas de sus enemigos y defen-

basado en qué principios se les niegan a los indígenas la propiedad de sus resguardos?". Informe del gobernador de la provincia de Lorica. Cartagena, 22-V-1864. Gaceta Oficial del Estado Soberano de Bolivar, BLAA.

68 Lei 4. Junio 23 de 1843. Sobre proteccion a los indíjenas, en Poмво, 1845, pp. 100-103.

69 Memorial del señor Victoriano Peña solicitando se ampare a los indígenas de Toluviejo en la posesión de su resguardo. Cartagena, 20-VI-1869. Gaceta de Bolivar, BLAA.

70 Memorial de varios vecinos del extinguido distrito de Malambo y resolución. Cartagena, 28-I-1869. Gaceta de Bolivar, BLAA. También ver Protocolización de una diligencia que acredita la propiedad de los Indíjenas del pueblo de Usiacurí, AHDA sección $1^{\mathrm{a}}$, fondo notarial: Notaria Única del Circuito de Sabanalarga, Libro de 1867-1869, tomo único, escritura $\mathrm{N}^{\circ}$. 16 fols. 1v-13r.; Protocolización de unas diligencias que acredita la propiedad de los indíjenas de Piojó, sobre los terrenos de su respetivos resguardos. AHDA, Notaria de Sabanalarga, Libro de 1867-1869, escritura $\mathrm{N}^{\circ}$. 12, fols. 20v-26r.; Representación de varios indígenas de Toluviejo y resolución. Cartagena, 20-IX-1873. Gaceta de Bolivar, BLAA. 
der sus intereses. Así, por ejemplo, en 1873 los indígenas de Guazo se organizaron en una sociedad basada en los principios modernos de la ciudadanía, crearon una junta directiva y cada miembro expresó su voluntad de defender las tierras de la comunidad. El paso inmediato que dieron fue elevar representaciones a las autoridades de la región pidiendo protección para sus derechos, y a la Corte Suprema de Justicia de los Estados Unidos de Colombia solicitando la derogación de las leyes aprobadas por la Asamblea Legislativa del Estado de Bolívar que iban en contravía con sus intereses. Pero también decidieron reconstituir el pequeño cabildo indígena y solicitaron a las autoridades judiciales de la provincia de Magangué el deslindamiento de las tierras del resguardo para evitar las usurpaciones a que estaban sometidos desde tiempo atrás ${ }^{71}$.

Años después, en 1899, el Tribunal de Justicia del departamento de Bolívar acogía los argumentos del abogado defensor de los indígenas de Malambo, quien arguyó que eran indígenas porque existía una serie de hechos (demandas, delimitación de linderos de tierras, pequeños cabildos, arrendamientos de tierras y relaciones de alteridades con otros sectores) en donde se autorreconocían y eran reconocidos por las autoridades y otros grupos como de esa condición racial ${ }^{72}$, lo que sin duda representaba un criterio avanzado para la época.

\section{REFERENCIAS BIBLIOGRÁFICAS}

\section{Fuentes Primarias Impresas:}

"Bando impreso dirigido a todos los estantes y habitantes de la provincia de Cartagena por el presidente de la Junta de Cartagena, José María García Toledo, 9 de noviembre de 1810". En GutiérRez - Martínez (eds.), La visión del Nuevo Reino de Granada en las Cortes de Cádiz (1810-1815). Bogotá. Academia Colombiana de Historia - Universidad Industrial de Santander. 2008, pp. 78-85.

Censo general de la República de Colombia levantado el 5 de marzo de 1912. Bogotá. Imp. Nacional. 1913,

Compilación de leyes del Estado Soberano de Bolívar 1857-1875. Cartagena. Tip. Araujo. 1876.

Leyes expedidas por la Asamblea Legislativa del Estado Soberano de Bolívar en sus sesiones ordinarias de 1878 y 1879. Cartagena. Tip. Araujo. 1880.

Leyes expedidas por la Asamblea Legislativa del Estado Soberano de Bolívar en sus sesiones ordinarias de 1880. Cartagena. Tip. Araujo. 1881.

Leyes expedidas por la Asamblea Legislativa del Estado Soberano de Bolívar en sus sesiones ordinarias de 1884. Cartagena. Tip. Araujo. 1884.

71 Flórez, 2009, pp. 49-72.

72 Manotas, 1899; Solano - FlóRez, 2009, pp. 267-295. 


\section{Bibliografía}

Appelbaum, Nancy

2007 Dos plazas y una nación: raza y colonización en Riosucio, Caldas 18461948. Bogotá. Instituto Colombiano de Antropología e Historia - Universidad de los Andes - Universidad del Rosario.

Arias, Julio

2005 Nación y diferencia en el siglo XIX colombiano. Bogotá. Universidad de los Andes.

ArIZA, Libardo

2009 Derecho, saber e identidad indigena. Bogotá. Siglo del Hombre Eds. - Universidad de los Andes - Universidad Javeriana.

Ausdal, Shawn van

2009 The logic of livestock: An historical geography of cattle ranching in Colombia, 1850-1950. Dissertation PhD. Berkeley. University of California.

BONFIL, Guillermo

1970 "El concepto de indio en América: una categoría de la situación colonial". Anales de Antropología. México, n7, pp. 105-124.

BonNETT, Diana

2002 Tierra y comunidad. Un problema irresuelto. El caso del altiplano cundiboyacense (Virreinato de la Nueva Granada) 1750-1800. Bogotá. Universidad de los Andes.

Botero, Clara

2007 "La construcción de discursos sobre el mundo prehispánico de Colombia durante el siglo XIX”. En Osorio, Construcción de la memoria indígena. Bogotá. Siglo del Hombre Eds. - Universidad de los Andes, pp. 85-101.

BRADING, David

1998 Orbe indiano: de la monarquía católica a la república criolla 1492-1867. México. Fondo de Cultura Económica.

Carmagnani, Marcello

2004 El regreso de los dioses. El proceso de reconstitución de la identidad étnica en Oaxaca. Siglos XVII y XVIII. México. Fondo de Cultura Económica.

Castro-Gómez, Santiago

2004 "Biopolíticas imperiales. Nuevos significados de la salud y la enfermedad en la Nueva Granada [1750-1810]”. En CAstro-Gómez, Pensar el siglo XIX. Cultura, biopolitica y modernidad en Colombia. Pittsburgh. Universidad de Pittsburgh, pp. 52-103.

2005 La hybris del punto cero. Ciencia, raza e ilustración en la Nueva Granada (1750-1816). Bogotá. Universidad Javeriana.

Colpas, Jaime - Mendoza, Cesar

1999 “Por qué desaparecieron los resguardos en el Partido de Tierradentro?”. Amauta. Barranquilla, n²12, pp. 54-58. 
CondE, Jorge

2002 Ensayos históricos sobre el departamento del Atlántico. Bogotá. Ministerio de Cultura.

CuÑo, Justo

2008 El retorno del Rey. El restablecimiento del régimen colonial en Cartagena de Indias [1815-1821]. Valencia. Universitat Jaume I.

ESCOBAR, Antonio

2010 "Del dualismo étnico colonial a los intentos de homogeneidad en los primeros años del siglo XIX latinoamericano". En Escobar - Falcón - Buve, La arquitectura histórica del poder. Naciones, nacionalismos y estados en América Latina. Siglos XVIII, XIX y XX. México. El Colegio de México CEDLA, pp. 41-57.

FALs, Orlando

1986 El Presidente Nieto. Bogotá. Carlos Valencia eds.

FLóREZ, Roicer

2009 "Indígenas y ciudadanía: el problema de los resguardos en el Estado Soberano de Bolívar, 1863-1875”. Historia y Sociedad. Medellín, nº16, pp. 49-72.

FRIEDE, Juan

1976 El indio en lucha por la tierra. Bogotá. Punta de Lanza.

Geografía eConómica de Colombia

1942 Bolivar. Bogotá. Contraloría General de la República.

GonZÁLEZ, Margarita

1992 El resguardo en el Nuevo Reino de Granada. Bogotá. El Áncora eds.

GoNZÁLEZ, María

1993 Resguardos coloniales de Santa Marta y Cartagena y resistencia indígena. Bogotá. Banco Popular.

Guarisco, Claudia

1995 El tributo republicano. Indios y Estado en el Ecuador: 1830-1857. Quito. FLACSO.

2004 Etnicidad y ciudadanía en México y Perú [1770-1850]. Tabasco. El Colegio Mexiquense.

GUTIÉRREZ, Jairo

2007 Los indios de Pasto contra la República [1809-1824]. Bogotá. Instituto Colombiano de Antropología e Historia.

HÉAU, Catherine

2009 "La reapropiación ideológica de la idea de 'raza' entre los campesinos morelenses a fines del siglo XIX y durante el Porfiriato". Cultura y Representaciones Sociales. México, vol. 3, nº, pp. 145-162. 
IRUROZQUI, Marta

1999 "Las paradojas de la tributación. Ciudadanía y política estatal indígena en Bolivia, 1825-1900”, Revista de Indias. Madrid, vol. LIX, n²17, pp. 705740.

2006 "Sobre el tributo y otros atributos ciudadanos. Sufragio censitario, fiscalidad y comunidades indias en Bolivia, 1825-1839". Bicentenario. Santiago, vol. $5, \mathrm{n}^{\circ} 2$, pp. 35-66.

LANGEBAEK, Carl

2009 Los herederos del pasado: indígenas y pensamiento criollo en Colombia y Venezuela. Bogotá. Universidad de los Andes. 2 vols.

LunA, Lola

1993 Resguardos coloniales de Santa Marta y Cartagena y resistencia indígena. Bogotá. Banco Popular.

Manotas, Avelino

1899 Recurso de casación. Juicio sobre vacancia del Resguardo Malambo-viejo. Barranquilla. Imp. de Los Andes.

MARTínez, Armando

1993 El régimen del resguardo en Santander. Bucaramanga. Gobernación de Santander.

Martínez, José - Gallardo, Viviana - Martínez, Nelson

2002 "Construyendo identidades desde el poder: los indios en los discursos republicanos de inicios del siglo XIX". En Boccara, Colonización, resistencia y mestizaje en las Américas (siglos XVI-XX). Quito. Abya-Yala. pp. 27-46.

Mendieta, Pilar

2005 "En defensa del pacto tributario. Los indígenas bolivianos frente al proyecto liberal: siglo XIX”. Revista Andina. Lima, n41, pp. 131-154.

Mosquera, Tomás C. de

1866 Compendio de Jeografía jeneral, política, fisica y especial de los Estados Unidos de Colombia Londres. H. C. Panzer.

MúnERA, Alfonso

2005 Fronteras imaginadas. Bogotá. Planeta.

Nieto, Juan José

1993 "Geografía histórica, estadística y local de la Provincia de Cartagena República de la Nueva Granada, descrita por Cantones" [1836]. En Bell, Juan José Nieto. Selección de textos políticos, geográficos e históricos. Barranquilla. Gobernación del Atlántico.

Pombo, Lino de (comp.)

1845 Recopilación de leyes de la Nueva Granada. Bogotá. Imp. de Zoilo Salazar.

RolDÁn, Roque (comp.)

1990 Fuero indigena colombiano. Bogotá. Presidencia de la República.

Ruiz, Julián

1996 Los indios de Cartagena bajo la administración española en el siglo XVII. Bogotá. Archivo General de la Nación. 
SAETHER, Steinar

2005a "Independence and the re-definition of indianness around Santa Marta, Colombia, 1750-1850". Journal of Latin American Studies. London, vol. 37, $\mathrm{n}^{\mathrm{o}} 1$, pp. 55-80.

2005b Identidades e independencia en Santa Marta y Riohacha, 1750-1850. Bogotá. Instituto Colombiano de Antropología e Historia.

SAFFORD, Frank

1991 "Race, integration, and progress: elite attitudes and the indian in Colombia, 1750-1870". Hispanic American Historical Review. Durham, vol. 71, nº', pp. 1-33.

SANDERS, James

2003 "Belonging, to the great Granada family: partisan struggle and the construction of indigenous identity and politics in southwestern Colombia, 1849-1890". En ApPelbaum - MacPherson - Rosemblatt, Race \& nation in modern Latin America. Chapel Hill. University of North Carolina, pp. 5685 .

2004 Contentious republicans: popular politics, race, and class in nineteenthcentury Colombia. Durham. Duke University.

Solano, Sergio Paolo

2008 "La novela Yngermina de Juan José Nieto y el mundo racial del Bolívar Grande en el siglo XIX”. Revista de Estudios Sociales. Bogotá, n³1, pp. 34-47.

Solano, Sergio Paolo - FlóRez, Roicer

2007a "Resguardos indígenas, ganadería y conflictos sociales en el Bolívar Grande, 1850-1875". Historia Crítica. Bogotá, pp. 92-117.

2007b "Expropiación de las tierras del resguardo indígena de Tubará y las normas jurídicas de la época". Justicia. Barranquilla, nº12, pp. 81-89.

2009 "Indígenas, mestizaje, tierras y poder en el Caribe colombiano, siglo XIX". Indiana. Berlín, n²6, pp. 267-295.

2011 Infancia de la nación. Colombia durante el primer siglo de la República. Bogotá. Eds. Pluma de Mompox.

Solano, Sergio Paolo - Flórez, Roicer - Malkún, William

2010 "Ganaderos y comerciantes: el manejo del poder político en el Estado Soberano de Bolívar (Colombia), 1857-1886". Historia y Sociedad. Medellín, $\mathrm{n}^{\circ} 18$, pp. 15-42.

Soux, María

2008 "Tributo, constitución y renegociación del pacto colonial. El caso altoperuano durante el proceso de independencia (1808-1826)". Relaciones. México, vol. XXIX, nº 115 , pp. 18-48.

Tovar, Hermes - Tovar, Jorge - Tovar, Camilo (comps.)

1994 Convocatoria al poder del número. Censos y estadísticas de la Nueva Granada, 1750-1830. Bogotá. Archivo General de la Nación. 
WADE, Peter

2007 "Identidad racial y nacionalismo: una visión teórica de Latinoamérica". En De La Cadena (ed.), Formación de la indianidad en América Latina. Popayán. Envión, pp. 379-402.

Zambrano, Carlos

2000 "La inacabada y porfiada construcción del pasado: política, arqueología producción de sentido en el macizo colombiano". En GNECCO - ZAMBRANO, Memorias hegemónicas, memorias disidentes. El pasado como política de la historia. Bogotá. Ministerio de Cultura - Instituto Colombiano de Antropología - Universidad del Cauca, pp. 195-229. 